\title{
CLOUD COMPUTING ARCHITECTURE FOR HIGHER EDUCATION IN THE THIRD WORLD COUNTRIES (REPUBLIC OF THE SUDAN AS MODEL)
}

\author{
Mohmed Sirelkhtem Adrees ${ }^{1}$, Majzoob Kamal Aldein Omer ${ }^{2}$ and \\ Osama E. Sheta ${ }^{3}$ \\ ${ }^{1}$ Department of Information System, AL Baha University, AL Baha, Saudi Arabia \\ ${ }^{2}$ Department of Computer Science, AL Baha University, AL Baha, Saudi Arabia \\ ${ }^{3}$ Department of Information System, AL Baha University, AL Baha, Saudi Arabia
}

\begin{abstract}
The exponential growth in the volume of data and information lead to problems in management, controlling effective and high costs of storage operation, where organizations are having problems: data retrieval and preparation and backups, and other acts of data. Therefore seeking companies and business organizations at the present time to achieve the highest return on their investments in technology through the planning and implementation of virtualization technologies and cloud computing, in order to protect data and manage more effectively and efficiently. We find that the government funding for higher education is decreasing continuously in third world countries, and the education management stand for a set of challenges. Cloud computing can help to provide solutions for these challenges, they bring multiple solutions cannot be applied to regular IT models.

This paper aims to discuss and analyzing: concepts of cloud computing, cloud computing models, cloud computing services, cloud computing Architecture and the main objective of this paper is to how to use and applied cloud computing Architecture in higher education, in third world countries, the republic of Sudan as a model.
\end{abstract}

\section{KEYWORDS}

Least developed country (LDC), cloud computing, cloud computing architecture, higher education. Cloud computing education.

\section{INTRODUCTION}

The National Institute of Standards and Technology NIST Definition of Cloud Computing: Cloud computing is a model for enabling ubiquitous, convenient, on-demand network access to a shared pool of configurable computing resources (e.g., networks, servers, storage, applications, and services) that can be rapidly provisioned and released with minimal management effort or service 
International Journal of Database Management Systems ( IJDMS ) Vol.7, No.3, June 2015

provider interaction. This cloud model is composed of five essential characteristics, three service models, and four deployment models.

In Cloud Computing the word cloud (also phrased as "the cloud") is used as a metaphor for "the Internet," so the phrase cloud computing means "a type of Internet-based computing," where different services — such as Servers, storage and applications - are delivered to an organization's computers and devices through the Internet [20]

Cloud computing: The very definition of cloud computing remains controversial. Consulting firm Accenture has crafted a useful, concise definition: the dynamic provisioning of IT capabilities (hardware, software, or services) from third parties over a network. [8]

Cloud computing evolved as a successful utility computing paradigm for Information and Communication Technology (ICT) resources delivery as a service over the Internet. The adoption of cloud computing spans across industry, government, and academia alike. [12]

The massive proliferation of affordable computers, Internet broadband connectivity and rich education content has created a global phenomenon in which information and communication technology (ICT) is being used to transform education. Cloud computing is beginning to play a key role in this transformation. [24]

Education transformations can transcend economic and social barriers, providing equal advantages and opportunities to everyone who has access to ICT. In Portugal, for example, it took just two years for a nationwide effort to transform education and achieve significant economic benefits. Computers are now available to every primary school student in the country - moving Portugal to the forefront of digital education while also creating nearly 1,500 new jobs and adding EUR 2.26 billion to the country's economy.[24]

\section{Cloud: OvervieW}

\subsection{Concepts of Cloud Computing :}

The services that are made through hardware and software connected to servers carry their data in a virtual cloud, ensure it relates to permanently without interruption, with different devices (computer, tablet device, smartphones, etc.) after placing a special code to open and lock the network, and thus are accessible from anywhere, at any time.

It is the transfer of the treatment process from the user's PC to the maid devices via the Internet, and save user files to be able to access them from anywhere and any device, and to become software services, and a digital user interface, and allows servers to multiple users using the same service.

Cloud is not simply the latest term for the Internet, though the Internet is a necessary foundation for the cloud, the cloud is something more than the Internet. The cloud is where you go to use technology when you need it, for as long as you need it. You do not install anything on your desktop, and you do not pay for the technology when you are not using tithe cloud can be both software and infrastructure. It can be an application you access through the Web or a server like Gmail and it can be also an IT infrastructure that can be used as per user's request.[1] The main 
International Journal of Database Management Systems ( IJDMS ) Vol.7, No.3, June 2015

enabling technology for cloud computing is virtualization. Virtualization software separates a physical computing device into one or more "virtual" devices, each of which can be easily used and managed to perform computing tasks. With operating system-level virtualization essentially creating a scalable system of multiple independent computing devices, idle computing resources can be allocated and used more efficiently. Virtualization provides the agility required to speed up IT operations, and reduces cost by increasing infrastructure utilization.[8] as shown in Figure 1.

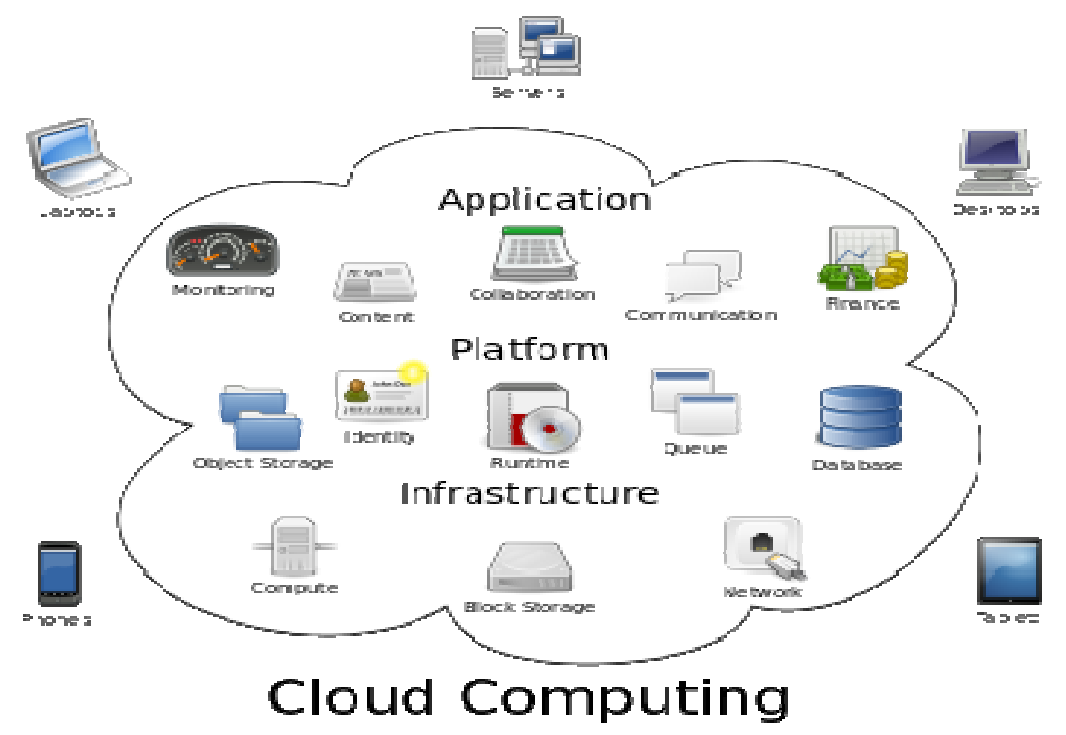

Figure 1. Cloud Computing Infrastructure

Table 1: concepts of computing terms

\begin{tabular}{|l|l|}
\hline The term & The meanings \\
\hline Resources or bundled sources & Available to all users and subscribers \\
\hline Virtualization & The use of high devices \\
\hline Flexibility & Control of resources and sources according to the need \\
\hline Automation & $\begin{array}{l}\text { Construction, deployment, configuration, and exchange, Without } \\
\text { manual intervention }\end{array}$ \\
\hline Cost bills & Pay only for use \\
\hline
\end{tabular}

\subsection{Requirements for the use of cloud computing:}

i. Personal computers allowed connecting to the Internet.

ii. Operating system allows connecting to the Internet.

iii. A high-speed connection to the Internet is a link between the user and the data and all the software it uses.

iv. Internet browser allows the use of cloud services

\subsection{Cloud Architecture:}

Cloud computing architecture refers to the components and subcomponents required for cloud computing. This section describes a layered model of cloud computing in which a cloud 
International Journal of Database Management Systems ( IJDMS ) Vol.7, No.3, June 2015

computing environment can be divided into four layers: the hardware/datacenter layer, the infrastructure layer, the platform layer and the application layer [25].

Cloud computing architecture refers to the components and subcomponents required for cloud computing. These components typically consist of a front end platform (fat client, thin client, mobile device), back end platforms (servers, storage), a cloud based delivery, and a network (Internet, Intranet, Intercloud). Combined, these components make up cloud computing architecture [22] shown in Figure 2,3

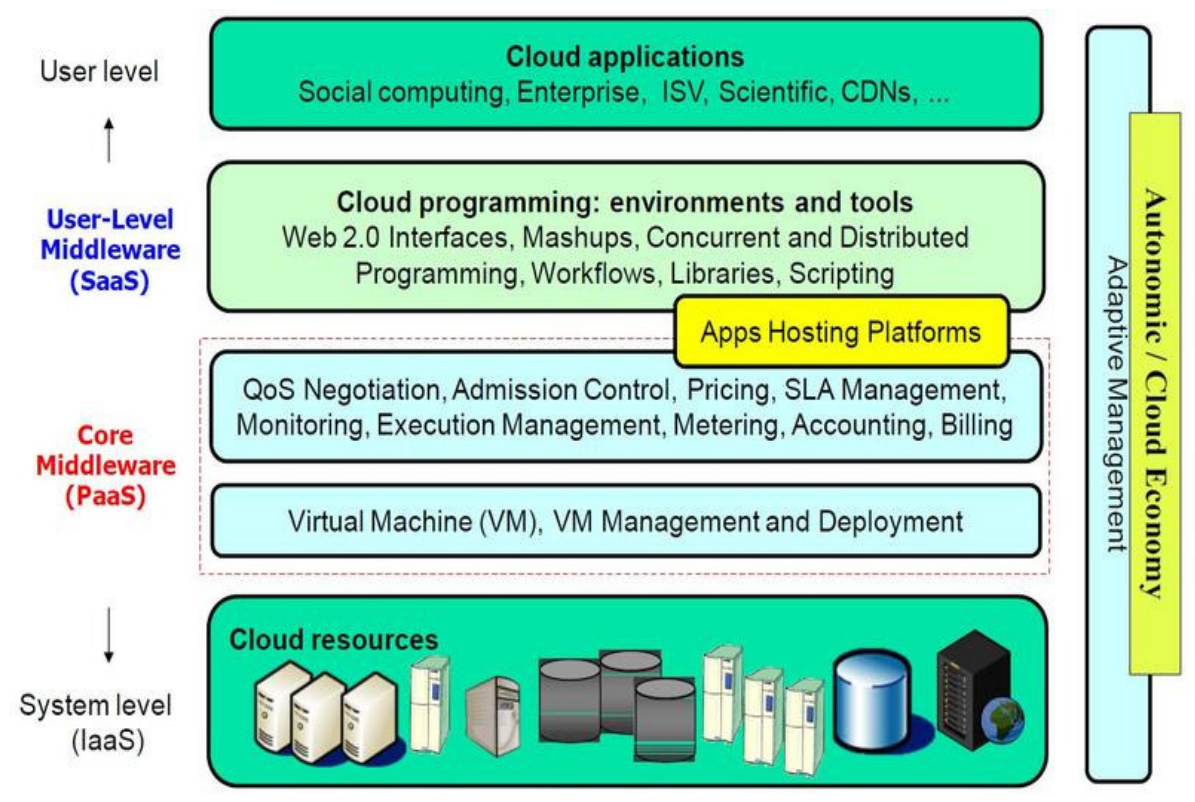

Figure 2. Cloud Computing Architecture

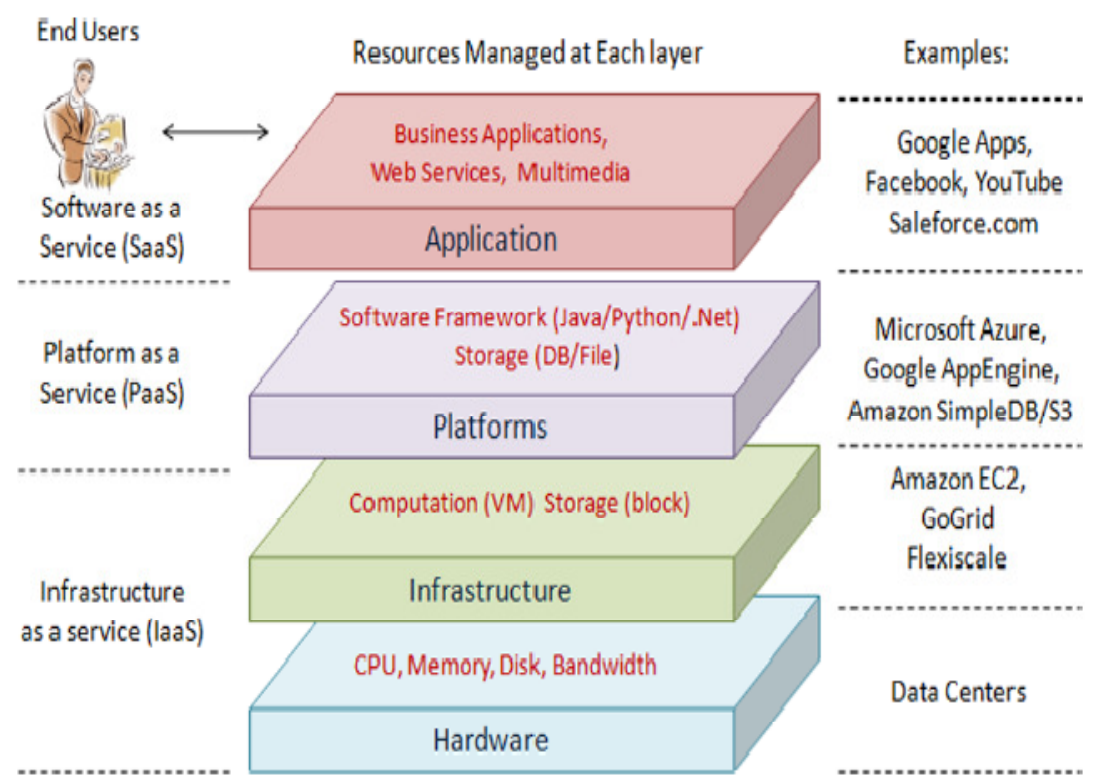

Figure 3. Cloud Computing Architecture 
International Journal of Database Management Systems ( IJDMS ) Vol.7, No.3, June 2015

\subsection{Cloud Services Models:}

Cloud computing providers offer their services according to several fundamental models.

\subsubsection{Infrastructure as a service (IaaS):}

It indicates that cloud computing infrastructure allows users to work as the default device from which to store files and documents and perform all processing operations online without limitations on the type of device used to access the cloud, in addition to improving networking operations.

\subsubsection{Platform as a Service (PaaS):}

Serves as the operating system, programming environment, database, Web server, and the user can handle it without any cost or the purchase of material or software components.

\subsubsection{Network as a Service (NaaS):}

Business model to provide network services on the basis of pay-per-use or subscription.

\subsubsection{Communication as a Service (CaaS) :}

SaaS is to add an additional layer based on session protocol and thus facilitate communication applications to run on the cloud as a service.

\subsubsection{Softform as s Service (SaaS):}

Is to run a variety of programs through the cloud server, this software does not require the user to purchase or installed across its hardware, and does not need to be re-configured, where the owner of the cloud is responsible for all these operations.

\subsubsection{Data as a Service (DaaS):}

It means the possibility of access to data on demand by the user at any time, and in any format, without regard to any differences between the supplier and the consumer, based on cloud computing.

\subsection{Deployment Model:}

The deployment models defined by the cloud community are Public Cloud, Private Cloud, Hybrid Cloud and Community Cloud.

Public Cloud: One of the leading forms of the current computing deployment model. Mainly used by the general public cloud consumer and the policy, value and costing are defined by the service provider. 
International Journal of Database Management Systems ( IJDMS ) Vol.7, No.3, June 2015

Private Cloud: Private cloud is cloud infrastructure dedicated to a particular organization. Private clouds allow businesses to host applications in the cloud, while addressing concerns regarding data security and control, which is often lacking in a public cloud environment.

Hybrid Cloud: Hybrid cloud is a cloud computing environment which uses a mix of on-premises, private cloud and public cloud services with orchestration between the two platforms.

Community Cloud: A community cloud in computing is a collaborative effort in which infrastructure is shared between several organizations from a specific community with common concerns (security, compliance, jurisdiction, etc.), whether managed internally or by a third-party and hosted internally or externally.

\subsection{Cloud Characteristics:}

Cloud computing a number of characteristics are as follows:

\subsubsection{Centralized user:}

When the user connects the cloud, it becomes the property of the stores, and can share with other users.

\subsubsection{Tasks Centralized:}

Focus on the needs of users through different applications.

\subsubsection{Infrastructure Centralized:}

Provide a huge cloud server that help in conducting operations which helps to escape the burdens of the establishment and management of infrastructure.

\subsubsection{Applications and documents Centralized:}

It is started, and stored, and edited, in the cloud through any device, connected to the Internet.

\subsubsection{Computing power:}

Produced through a link from thousands of devices and servers together.

\subsubsection{Access:}

It allows retrieving more information from warehouses cloud.

\subsubsection{Flexibility:}

Cloud computing to provide more flexibility in access to resources, information technology, and business functions. 
International Journal of Database Management Systems ( IJDMS ) Vol.7, No.3, June 2015

\section{ClOUd COMPUTING IN EDUCATION}

Cloud computing services is one of the forms of modern virtualization software used on a large scale in the business sectors and government services and electronic transactions in the majority of countries in the world, but they recently put forward an idea to be used in the areas of distance education and e-learning, with the proliferation of cloud computing is no longer a matter just a theoretical concept but turned into concrete application we are seeing in a number of services in the Web, especially in the field of e-learning, for example, it moved to build tests of software that can be downloaded to the device to the services on the Internet does not require any special software to take advantage of them process, The location (classmarker.com) and service (quizschool), for example, benefited from the capabilities of cloud computing to provide hosting Testing Service and evaluated automatically for free or for a nominal fee, where two sites offer the possibility of the work of tests of various types, such as complete vacuum, multiple-choice, true and error, and others, with the provision of the ability to display the questions randomly or according to a particular order, and the dissemination of the test via e-mail or Web pages.

The education industry now faces a new set of challenges that is driving a fundamental transformation across the education. Their customer demographics, behaviors and expectations have changed. They face revenue pressures along with increasing sensitivities from their customers on the return on investment for dollars spent on higher education. [11]

At the same time, education institutions are under increasing pressure to deliver more for less, and they need to find ways to offer rich, affordable services and tools. Those educators who can deliver these sophisticated communications environments, including the desktop applications that employers use today, will be helping their students find better jobs and greater opportunities in the future.[2]

Despite all of advantages of cloud, computing it still not fully adopted in academic institutions sector. It is only $4 \%$ of cloud computing used in education and the other $96 \%$ is related to industrial sectors and services [6].

The educational cloud computing industry is still in the beginning. Nevertheless, cloud computing has potential to play a wide and significant role in education technology in the near future. It is because now cloud computing spreads fast in all industries.

Cloud computing service offers many advantages for learners, such as testing directly (online),easy to send exercises and projects for learners, easy access to the tests, exercises, projects submitted by students, feedback between students and teachers, easy of communication between students, help students and teachers to use applications without loaded on their computers and help them to access stored files from any computer by using the Internet and the student can access all programs at any time, from anywhere.

Thus, it was possible to harness cloud computing service in the educational objectives service in several areas, including the provision of lectures or seminars quota from a distance, so that they are present on the virtual cloud (which may be in the form of a website or application on smart tablets or mobile), and can be accessed her away from the barriers of time or place. 


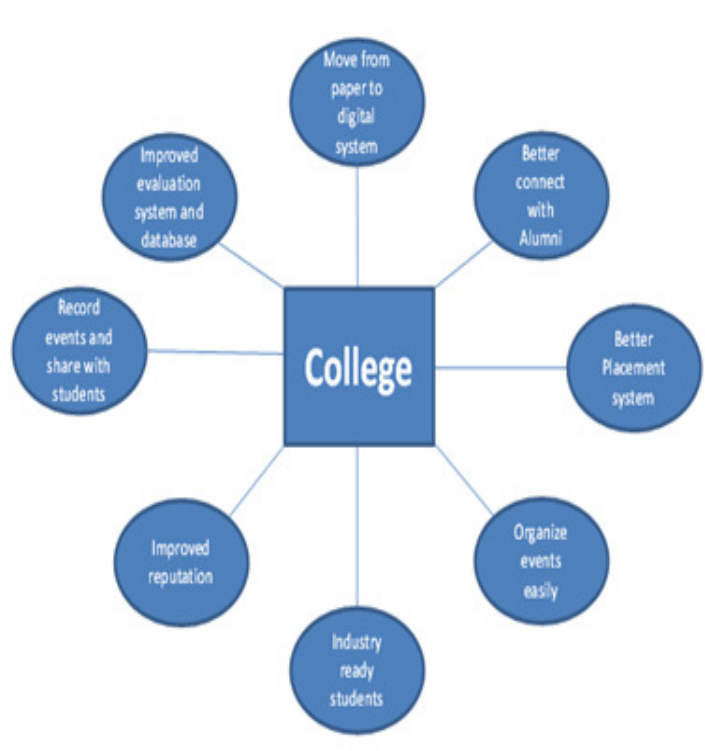

College Activities

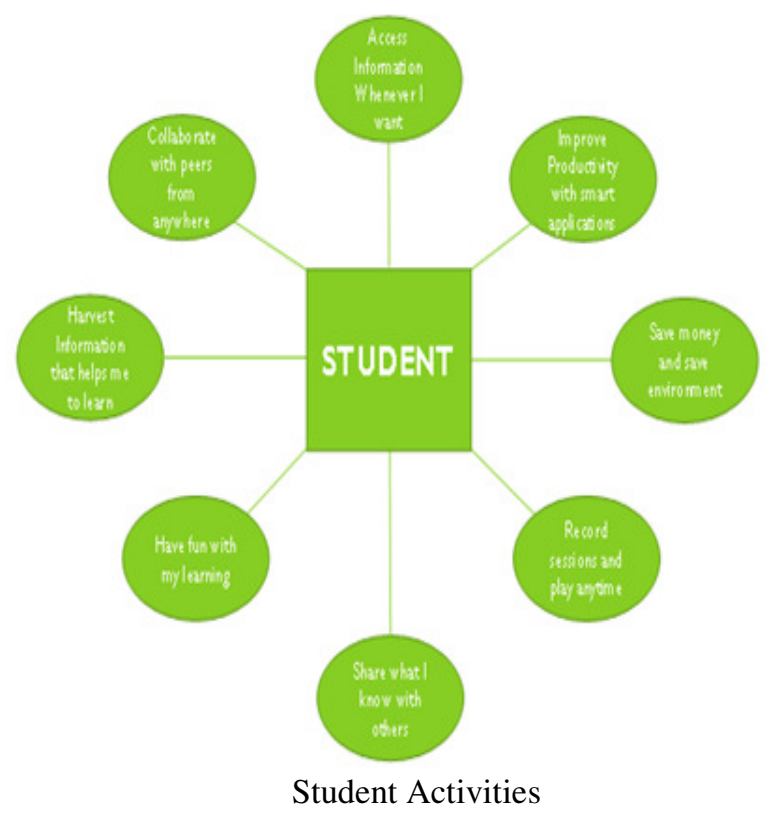

Student Activities

Figure4: Student and Activities

\section{SERVICES AVAILABLE TO EDUCATIONAL INSTITUTIONS}

Leading cloud providers have recognized the importance of adjusting their computing services specifically to the needs of educational institutions. Some of the most widely used educational platforms are listed below:

1- Microsoft for Education: Microsoft educational tools is a set of programs and websites geared mainly to students to help them to gain time and learning in an innovative way, as it is also intended for teachers to develop their performance and make professional practices more attractive, through the optimum exploitation of what can be granted by the technology in the field of Education.

2- Google Apps for Education: A set of tools and participatory and collaborative solutions provided by Google, and that can be used by workers to the field of education. Google's applications characterized by several properties rarely meet in cooperative solutions to other companies, making many of educational institutions choose to cooperative solutions to Google on its way towards the world of technology.

3- Amazon Web Services for Education (AWS): Is an easy range of services, which provides effective solutions in terms of cost, in universities, community colleges and vocational schools. AWS can contribute to the creation of infrastructure for information technology flexibility in these institutions. 
International Journal of Database Management Systems ( IJDMS ) Vol.7, No.3, June 2015

\section{Cloud COMPUTING IN Higher EduCATION IN THE THIRD WORLD COUNTRIES}

In most developing countries, few children graduate from secondary school and many do not even finish primary school. In Ghana, for example, only 50 percent of children complete grade 5, and of those, less than half can comprehend a simple paragraph. [17]

The biggest threat to universal education is quite simply a lack of funding. Many of the teachers in third world countries are volunteers. Certainly, they are great assets and a huge need in third world countries. However, to bring in college-educated teachers would require funds that they simply do not have. There are some college educated teachers in third world countries but often they work for little or no money at all. There is a huge need for college and university educated teachers and for adequate classrooms. Many of the classrooms have few books and not near enough supplies. Supplies that large countries take for granted are in fact in short supply in these other countries. Things like notebooks, papers, pens, and folders are in very short supply in third world countries. [13]

Over the past decade, education industry has grown significantly in the Sudan.

This development in education and faced challenges, such as lack of government spending on education and the loss of professors collectors because of migrations and there is dearth of qualified teachers in the country.

Posing a major challenge for institutions Sudanese Higher Education to continue to do their job, the most important of these solutions is to cut spending and to provide a suitable environment for education is the cloud of the best solutions to these problems.

There are a range of educational and technical problems in the least developed countries, especially in Sudan that occurred in previous years, to clarify and highlight:

1. Weakness of government funding for the education sector

2. The lack of infrastructure and buildings suitable for higher education

3. Migrations teaching staff

4. Lack of educational materials (books - References - Software - Tools assistant)

Through cloud computing to give some solutions, such as:

1. Virtualization of computing environment

2. Elastic Cloud storage.

3. Online course delivery.

4. Online assignments and tests.

5. Consolidated email services with Cloud

6. Project collaboration

7. Greater class participation.

8. Security. 
International Journal of Database Management Systems ( IJDMS ) Vol.7, No.3, June 2015

\section{CONCLUSIONS}

In the near future of cloud computing in the field of education service will become an essential source of e-learning in order to give the opportunity for students and teachers to quick access to various applications, systems and resources through the Internet, and share files and documents, and the exchange of duties and projects among students, a challenge that must overcome the comprehensive coverage of the service and fast Internet access, to enable the student to take advantage of this technology applications.

Cloud computing is the solution for a large part of the problems of education in the least developed countries, but the challenge remains in the political and administrative decision to adopt cloud computing in education

Through the provision of infrastructure, software as a service there are a lot of benefits of the educational institution in the less developed countries such as: enables education institutions to focus on the quality of education and the development of the human element and the use of resources in achieving educational goals without the need to invest in the purchase and maintenance of technical infrastructure.

And help in multiple classroom management through a small group of teachers and will help to overcome the problem of shortage of skilled teachers.

Cloud services can be a cheaper option for educational institutions facing cuts in funding, but still need to invest in technology to improve learning levels. As is the case in the least developed countries.

\section{REFERENCES}

[1] Ahmed. Gamaleldin .2013An Introduction to Cloud Computing Concepts :Practical Steps for Using Amazon EC2 IaaS Technology.

[2] A Microsoft U.S. Education white paper "Cloud computing in education Savings, flexibility, and choice for IT"2010.

[3] Amazon. 2012. AWS in Education Customer Experiences.

[4] awshttp://aws.amazon.com/education/customer-experiences/\#6.Accessed: 2012-07-18.

[5] Buyya, R., Broberg, J. \& Goscinski, A. 2011. Cloud Computing: Principles and Paradigms. John Wiley \& Sons,Inc.

[6] Bittman, T. 2009. Cloud Computing Inquiries at Gartner.

[7] Bansal, S.Singh, S., Kumar, A. 2012. Use of Cloud Computing in Academic Institutions. International Journal of Computer Science And Technology. 3, 1 (2012), 427- 429.

[8] CXOhttp://www.cio.com/article/2424886/cloud-computing/cloud-computing-definitions-andsolutions.html.

[9] Cloud computing in Telecommunications" . Ericsson. Retrieved 16 December 2012. 
International Journal of Database Management Systems ( IJDMS ) Vol.7, No.3, June 2015

[10] ciscohttps://www.cisco.com/web/strategy/education/cloud_computing.html.

[11] Cognizant Cloud Services "Harnessing Cloud Computing In Education”.2014

[12] R. Buyya, C. S. Yeo, S. Venugopal, J. Broberg, and I. Brandic, "Cloud computing and emerging IT platforms: Vision, hype, and reality for delivering computing as the 5th utility," Future Generation Computer Systems, vol. 25, no. 6, pp. 599-616, Jun. 2009

[13] hewletthttp://www.hewlett.org/programs/global-development-population/quality-education.

[14] HAMDAQA, Mohammad (2012). Cloud Computing Uncovered: A Research Landscape (PDF). Elsevier Press. pp. 41-85. ISBN 0-12-396535-7.

[15] IBM Cloud Academic. 2012.A Collaborative Community of Leaders: Cloud Computing in Education. http://www.ibm.com/solutions/education/cloudacademy/us/en/cloud_academy_4.html

[16] Singh, A. and Hemalatha, M. 2012. Cloud Computing for Academic Environment. 2, 2 (2012), 97101

[17] ssireviewhttp://www.ssireview.org/articles/entry/redefining_education_in_the_developing_world

[18] The NIST Definition of Cloud Computing "Recommendations of the National Institute of Standards and Technology".

[19] unitarhttp://www.unitar.org/resource/sites/unitar.org.resource/files/document-pdf/GA-2767-

XXVI.pdf.

[20] Webopedia,http://www.webopedia.com/TERM/C/cloud_comp uting.html

[21] WHITE PAPER , Intel® World Ahead , Cloud Computing 2010 " The Education Cloud:Delivering Education as a Service"

[22] wikipediahttp://en.wikipedia.org/wiki/Cloud_computing_architecture

[23] wikipediahttp://en.wikipedia.org/wiki/Cloud_computing

[24] WHITE PAPER , Intel® World Ahead , Cloud Computing 2010 " The Education Cloud:Delivering Education as a Service".

[25] Zhang-Qi, Cheng-Lu, and Boutaba-Raouf. 2010. Cloud computing: state-of the-art and research challenges. J Internet Serv Appl (2010) 1: 7-18. 
International Journal of Database Management Systems ( IJDMS ) Vol.7, No.3, June 2015

\section{AUTHORS}

Dr.Mohmed Sirelkhtem Adrees; PhD (Information System), 3 years' experience, Assistant Professor (IS) Faculty of Science, Al Baha University, KSA.

Dr. Majzoob Kamal Aldein Omer; PhD (Information Technology), Assistant professor and Head of Computer Science, Department at AL Baha University since 2013, faculty of Sciences \& Arts, KSA . Assistant professor at AL Neelain University, Faculty of Computer Science and Information Technology from 2011 to 2013, Khartoum, Sudan.

Dr. Osama E. Sheta; PhD (Irkutsk State Technical University, Irkutsk, Russia). Assistant Professor (IS) Faculty of Science, Zagazig University, Egypt. Assistant Professor (IS) Faculty of Science, Al Baha University, KSA.
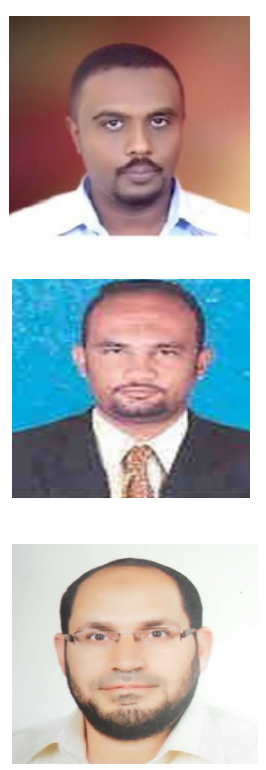